\title{
Hormone replacement therapy is associated with improved survival in women undergoing coronary artery bypass grafting
}

Nancy A. Nussmeier, MD

Maria Rosa Marino, MD

William K. Vaughn, PhD

From the Departments of Cardiovascular Anesthesiology and Biostatistics/Epidemiology, Texas Heart Institute at St Luke's Episcopal Hospital, Houston, Tex.

Received for publication Aug 30, 2001; revisions requested Jan 14, 2002; revisions received March 13, 2002 accepted for publication March 13, 2002.

Address for reprints: Nancy A. Nussmeier, MD, Director of Cardiovascular Anesthesia Research, Department of Cardiovascular Anesthesiology, Texas Heart Institute, 6720 Bertner Ave, Room O-520 (MC 1-226), Houston, TX 77225-0345 (E-mail: nnussmeier@heart.thi.tmc.edu).

J Thorac Cardiovasc Surg 2002;124:1225-9

Copyright $(\odot 2002$ by The American Association for Thoracic Surgery

0022-5223/2002 \$35.00+0 $\quad \mathbf{1 2 / 1 / 1 2 6 2 2 5}$

doi:10.1067/mtc.2002.126225
Objectives: The effect of hormone replacement therapy on cardiovascular events in postmenopausal women is controversial. We investigated the roles of sex and hormone replacement status in female patients undergoing coronary artery bypass grafting.

Methods: We reviewed the records of 4259 consecutive patients aged 55 years or older who underwent primary elective isolated coronary artery bypass at our hospital between May 1996 and September 2001.

Results: Female sex with hormone replacement therapy was an independent predictor of decreased mortality, regardless of age. Mortality was 6.7\% (61/905) for women not receiving hormone replacement therapy, $2.3 \%$ (6/256) for hormone replacement therapy recipients, and $2.7 \%(82 / 3098)$ for men $(P<.01$ for all comparisons). Of the characteristics examined, multivariate analysis indicated that independent predictors of mortality were advanced age, previous congestive heart failure, class IV angina, and female sex without hormone replacement $(P<.005)$. Independent predictors of survival included use of an internal thoracic artery graft and white ethnicity. There were no significant intergroup differences in the incidence of nonfatal, morbid postoperative events.

Conclusions: Postmenopausal women undergoing coronary artery bypass had a significantly improved in-hospital survival if they had been receiving hormone replacement therapy. The improved survival might be related to one or more of the numerous cardiovascular effects of estrogen that are considered beneficial. A prospective randomized trial is needed to validate the observation that hormone replacement therapy is protective in this setting.

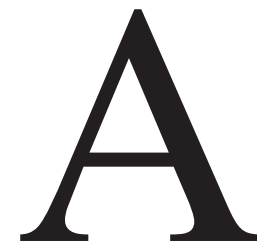

mong patients undergoing coronary artery bypass grafting $(\mathrm{CABG})$, the in-hospital mortality has consistently been higher in women than in men. ${ }^{1,2}$ Explanations for this difference have focused primarily on the more frequent comorbidity that is predictive of a poor outcome in women. In some studies statistical adjustment of mortality for risk-factor profiles eliminated female sex as an independent predictor. ${ }^{1,3,4}$ In the largest CABG database, however, female sex remained an independent predictor, despite risk-factor adjustment. ${ }^{2}$

None of these studies explored the possible role of hormone replacement therapy (HRT) in perioperative mortality. Such therapy is not recommended for secondary prevention of cardiovascular disease and is controversial, even for primary prevention. ${ }^{5-7}$ Nevertheless, investigators have described numerous cardiovascular effects of estrogen that are considered beneficial, ${ }^{8}$ including attenuation of adverse responses to endoluminal vascular trauma. ${ }^{9}$ Limited clinical studies suggest that HRT in postmenopausal women favorably affects long-term outcome after the endolu- 
minal trauma of coronary angioplasty and CABG. ${ }^{10-12}$ Shackelford and colleagues ${ }^{13}$ recently assessed the mortality after isolated CABG in 734 consecutive women, of whom 102 had received HRT preoperatively. On univariate, but not multivariate, analysis, the in-hospital mortality was significantly lower in the women who received HRT $(2.7 \%$ vs $7.4 \%$ ). The present study was undertaken to obtain additional data regarding the attractive hypothesis that HRT improves the in-hospital outcomes of cardiovascular surgical procedures that induce endoluminal vascular injury.

\section{Methods}

This retrospective analysis was performed on a comprehensive, prospectively collected database that included all patients treated at the Texas Heart Institute since 1993. (Completed patient charts are routinely abstracted, and data relating to risk factors and outcomes are entered into the database.) This study included 4259 consecutive men and women aged 55 years or older who underwent primary elective CABG with cardiopulmonary bypass between May 1996 and September 2001, without concomitant procedures, such as valve or ventricular aneurysm repair. The 55-year cut-off point for postmenopausal status is widely used.12,14-16 Female patients were classified as receiving HRT if oral or transdermal estrogen replacement or combined estrogen-progesterone replacement therapy was recorded in the physician's notes or the nurse's patient-admission assessment, which includes a list of current medications. All other patients were classified as not receiving HRT. For female patients receiving HRT, the first two thirds $(172 / 256)$ of the hospital records were rechecked to verify documentation of HRT status at the time of admission; no errors were found. Duration of HRT was not recorded in the database. In no instance, however, was HRT initiated by the admitting physician.

All analyses involved 3 groups: women not receiving HRT, women receiving HRT, and men. These were the primary predictor variables, with women without HRT serving as the reference group. Other potential preoperative predictor variables included age, body mass index, race (white vs nonwhite), preoperative ejection fraction, number of diseased coronary vessels, diabetes (with or without insulin dependence), history of congestive heart failure, unstable angina, previous myocardial infarction, tobacco use, peripheral vascular disease with or without intervention, hypertension, chronic obstructive pulmonary disease or asthma, or dialysis-dependent renal failure. The potential influence of preoperative concurrent therapy, including angiotensin-converting enzyme inhibitors, calcium-channel blockers, $\beta$-blockers, antihyperlipidemic agents, and aspirin, was also included in the analysis. Potential perioperative predictor variables included the number of vessels bypassed and use of an internal thoracic artery (ITA) graft.

The primary outcome variable was in-hospital mortality. Secondary outcome variables included major perioperative morbidity, such as myocardial infarction, use of an intra-aortic balloon pump, stroke, new onset of renal failure necessitating dialysis, postoperative infection, respiratory insufficiency (when diagnosed by a pulmonary specialist), postoperative bleeding necessitating re-exploration, and thromboembolic events (deep venous thromboembolism or pulmonary embolism). Univariate associations between potential predictors and outcome were assessed by means of $\chi^{2}$ analysis, followed by stepwise logistic modeling, which examined all significant predictors $(P=.10)$ for all groups.

\section{Results}

Of the 4259 patients in this study, 1161 were women, of whom $256(22.0 \%)$ were receiving HRT at hospital admission. This incidence of HRT is similar to the $20 \%$ estrogenuse rate reported by the National Center for Health Statistics. ${ }^{17}$ Of the 256 HRT recipients, $85 \%$ took conjugated estrogen (Premarin) or estradiol (Estrace or Estraderm) only. The remainder took a combination of conjugated estrogen and medroxyprogesterone acetate (Prempro, Premphase, or Premarin plus Provera).

The in-hospital mortality for all patients was $3.5 \%$. For women not receiving HRT, the mortality was $6.7 \%$ compared with $2.3 \%$ for women receiving HRT and $2.7 \%$ for men $(P=.008$ compared with HRT recipients and $P<$ .0001 compared with men by means of univariate analysis). Multivariate analysis confirmed that female sex without HRT was an independent predictor of increased in-hospital mortality $(P<.005)$.

Preoperative patient characteristics, intraoperative data, and length of hospital stay for the 3 groups were compared (Table 1). Compared with women receiving HRT, the women not receiving HRT were older (by 2.4 years, $P<$ $.0001)$, were more likely to be nonwhite $(P<.0001)$, were more likely to have a history of diabetes $(P<.007)$ and congestive heart failure $(P=.002)$, had more diseased vessels $(P=.0002)$, and had more vessels bypassed $(P=$ .002). Women receiving HRT were more often smokers $(P=.04)$, had a higher incidence of hypertension $(P=.04)$, and had more frequent use of an ITA graft $(P=.003)$.

Multivariate analysis for independent predictors of mortality indicated that female sex without HRT significantly predicted higher in-hospital mortality (Table 2). Other independent predictors were advanced age, history of congestive heart failure, and class IV angina. Independent predictors of survival included use of an ITA graft and white race (Table 2).

The mortality of all the women in this study was examined in terms of precipitating and ultimate causes to identify possible differences in patterns of mortality between women receiving and not receiving HRT. The result was unrewarding because of the small number of deaths in the HRT group $(n=6)$. In both groups approximately $50 \%$ of the deaths were primarily cardiac (ie, related to cardiogenic shock, myocardial infarction, arrhythmia, or congestive heart failure), and $13 \%$ were primarily related to the central nervous system (stroke and encephalopathy). Other causes of death included respiratory failure, renal failure, gastrointestinal complication, hemorrhage, sepsis, pulmonary embolus, and multiorgan system failure. The pattern of postoperative morbidity among the 3 groups was similarly compared 
TABLE 1. Patient characteristics

\begin{tabular}{|c|c|c|c|}
\hline Characteristics & $\begin{array}{c}\text { Women } \\
\text { receiving HRT } \\
(\mathrm{n}=256)\end{array}$ & $\begin{array}{c}\text { Women not } \\
\text { receiving HRT } \\
\text { (n }=905)\end{array}$ & $\begin{array}{c}\text { Men } \\
(\mathrm{n}=\mathbf{3 0 9 8})\end{array}$ \\
\hline Age $(y)$ & $68.0 \pm 7.8$ & $70.4 \pm 8.0 \dagger$ & $67.1 \pm 7.7$ \\
\hline Body mass index $\left(\mathrm{kg} / \mathrm{m}^{2}\right)$ & $27.6 \pm 5.5$ & $28.1 \pm 6.2$ & $27.9 \pm 5.0$ \\
\hline White ethnicity (\%) & 85.2 & $69.8 \ddagger$ & $72.2 \ddagger$ \\
\hline Diabetes $(\%)$ & 29.3 & $38.6 \dagger$ & 31.1 \\
\hline Ejection fraction (\%) & $53.0 \pm 11.8$ & $51.4 \pm 14.3$ & $48.7 \pm 13.4 \dagger$ \\
\hline NYHA class IV angina $(\%)$ & 13.3 & 16.0 & $11.3 \S$ \\
\hline No. of vessels diseased* & $1.7 \pm 0.9$ & $1.9 \pm 1.0$ & $2.1 \pm 0.9$ \\
\hline \multicolumn{4}{|l|}{ History of: } \\
\hline Tobacco use $(\%)^{*}$ & 40.0 & 33.0 & 53.2 \\
\hline Congestive heart failure (\%) & 20.7 & $30.8 \dagger$ & 19.0 \\
\hline Previous $\mathrm{MI}(\%)$ & 35.9 & 39.1 & 40.5 \\
\hline Hypertension $(\%)^{*}$ & 84.8 & 79.1 & 70.2 \\
\hline Peripheral vascular disease (\%) & 24.2 & 28.5 & $19.5 \S$ \\
\hline Renal failure $(\%)$ & 0.39 & 0.11 & 0.23 \\
\hline COPD $(\%)$ & 10.9 & 12.4 & 10.3 \\
\hline Preoperative IABP (\%) & 1.2 & 1.1 & 1.2 \\
\hline Use of an ITA graft $(\%)^{*}$ & 84.4 & 75.7 & 89.7 \\
\hline Duration of CPB (min) & $58.1 \pm 32.9$ & $62.5 \pm 36.2$ & $64.5 \pm 32.7 \ddagger$ \\
\hline No. of vessels bypassed* & $2.7 \pm 1.0$ & $2.9 \pm 1.1$ & $3.3 \pm 1.1$ \\
\hline Postoperative hospital stay (d) & $9.8 \pm 7.7$ & $10.2 \pm 7.7$ & $9.4 \pm 8.7 \S$ \\
\hline
\end{tabular}

Values are presented as means \pm SD. NYHA, New York Heart Association; MI, myocardial infarction; COPD, chronic obstructive pulmonary disease; IABP, intra-aortic balloon pump; $C P B$, cardiopulmonary bypass.

${ }^{*} P<.05$ for all comparisons among groups.

$\dagger P<.05$ versus both other groups.

$\ddagger P<.05$ versus women receiving HRT.

$\S P<.05$ versus women not receiving HRT.

(Table 3). There were no significant differences in morbidity related to HRT.

\section{Discussion}

Women undergoing CABG consistently have a higher operative mortality than men, ${ }^{1,2}$ but there is no agreement as to whether female sex, per se, is an independent risk factor. In several reports that have shown a higher in-hospital mortality in women, investigators have used various statistical models to adjust for body surface area, coronary artery size, or risk-factor profile. ${ }^{1,3,4}$ With such adjustments, the malefemale difference tended to lose significance. However, in the largest database, which included 97,153 women and 247,760 men who underwent isolated CABG between 1994 and 1996, women still had a significantly higher operative mortality $(4.5 \%$ vs $2.6 \%),{ }^{2}$ even when confounding risk factors were adjusted. This observation was reaffirmed in a reanalysis of these data. ${ }^{18}$ In none of the studies cited above was HRT examined as a predictor of mortality. Our data support female sex as an independent predictor of mortality and further suggest that HRT reduces risk in women to that in men.

The effect of HRT on the cardiovascular system is not clear. ${ }^{5-8,19} \mathrm{~A}$ large number of observational studies suggested that HRT offers substantial cardiovascular bene-
TABLE 2. Multivariate preoperative predictors of mortality or survival after CABG

\begin{tabular}{lccc}
\hline & OR & 95\% CI & P value \\
\hline Predictors of mortality & & & \\
Age $\geq 75$ y & 4.0 & $2.3-6.8$ & $<.0001$ \\
Age 65-75 y & 2.5 & $1.5-4.3$ & .0004 \\
$\quad$ Previous congestive heart failure & 3.4 & $2.4-4.9$ & $<.0001$ \\
Class IV angina & 1.7 & $1.1-2.7$ & .02 \\
$\quad$ Female sex without HRT & 1.7 & $1.2-2.5$ & .004 \\
Predictors of survival & & & \\
$\quad$ Use of an ITA graft & 0.6 & $0.4-0.9$ & .006 \\
$\quad$ White race & 0.6 & $0.4-0.8$ & .003 \\
\hline
\end{tabular}

Only predictor variables significant in the multivariate analysis are included (see the "Methods" section for list of all variables analyzed). OR, Odds ratio; $\mathrm{Cl}$, confidence interval.

fits. ${ }^{20-22}$ However, the results of large, prospective, randomized controlled clinical trials designed to study the effects of HRT in women with or without known coronary artery disease-the Heart and Estrogen/Progestin Replacement Study, ${ }^{14}$ the Estrogen Replacement and Atherosclerosis tri$\mathrm{al}^{15}$ and the Women's Health Initiative study ${ }^{7}$ - showed no significant benefit and raised the possibility of short-term increases in risk. For secondary prevention of cardiovascu- 
TABLE 3. Morbidity after CABG

\begin{tabular}{lcrr}
\hline Complications & $\begin{array}{c}\text { Women } \\
\text { receiving HRT } \\
(\mathbf{n}=\mathbf{2 5 6 )}\end{array}$ & $\begin{array}{c}\text { Women not } \\
\text { receiving HRT } \\
\text { (n= } \mathbf{9 0 5 )}\end{array}$ & $\begin{array}{c}\text { Men } \\
\text { (n= 3098) }\end{array}$ \\
\hline Myocardial infarction & $11(4.3 \%)$ & $29(3.2 \%)$ & $101(3.3 \%)$ \\
Intra-aortic balloon pump & $4(1.6 \%)$ & $5(0.6 \%)$ & $21(0.7 \%)$ \\
Stroke & $8(3.1 \%)$ & $44(4.9 \%)$ & $112(3.6 \%)$ \\
Renal failure & $2(0.8 \%)$ & $21(2.3 \%)$ & $43(1.4 \%)$ \\
Any infection & $19(7.4 \%)$ & $85(9.4 \%)$ & $208(6.7 \%)^{*}$ \\
Respiratory failure & $30(11.7 \%)$ & $97(10.7 \%)$ & $310(10.0 \%)$ \\
Postoperative reoperation for bleeding (\%) & $10(3.9 \%)$ & $30(3.3 \%)$ & $138(4.5 \%)$ \\
Thromboembolic event & $1(0.4 \%)$ & $8(0.9 \%)$ & $8(0.7 \%)$ \\
\hline
\end{tabular}

${ }^{*} P<.05$ versus women not receiving HRT.

lar events, the latest American Heart Association recommendations state that combinations of estrogen plus progesterone should not be initiated for this purpose. ${ }^{5,7}$ Definitive evidence regarding the benefits and risks of estrogen administered alone (without progesterone) for primary prevention of cardiovascular disease should emerge from the ongoing branch of the Women's Health Initiative trial involving women who had a hysterectomy, to be completed in $2005 .^{7}$

It is possible that the benefits of HRT are most evident in the presence of vascular injury, as noted in numerous laboratory studies. ${ }^{9,23-28}$ It has been clearly shown that endothelial cells and vascular smooth muscle cells possess estrogen receptors and that estrogen modulates the vascular responses to numerous endogenous hormones. In animal models of endoluminal injury of normal blood vessels, estrogen inhibits the hyperproliferation resulting from activation of adventitial cells and their migration toward the lumen. ${ }^{29}$ In the rat model with a balloon-injured common carotid artery, Oparil and colleagues ${ }^{9,23-28}$ showed that estrogen inhibited neointima formation by affecting all 3 layers of the vascular wall, inhibiting medial smooth muscle cell migration and proliferation, stimulating regrowth of the endothelium, and inhibiting adventitial-cell migration into neointima. Other data suggest women receiving HRT have greater endogenous fibrinolysis ${ }^{30}$ and that estrogen modifies the inflammatory response to reperfusion injury in animals. ${ }^{31,32}$ It is not at all clear which aspect of estrogen's action might mediate a benefit in the presence of vascular injury.

Some clinical data support the benefits of estrogen in the presence of vascular injury. Shlipak and colleagues ${ }^{16}$ studied 114,724 women aged 55 years or older with confirmed myocardial infarction participating in the National Registry of Myocardial Infarction 3. At hospitalization, 7353 (6.4\%) reported current use of HRT. Unadjusted mortality was $7.4 \%$ in users of HRT and $16.2 \%$ in nonusers (odds ratio, 0.41 ; confidence interval, 0.36-0.43). O'Keefe and coauthors ${ }^{10}$ retrospectively studied 337 postmenopausal women undergoing elective percutaneous transluminal coronary an- gioplasty, of whom 137 were consecutive women receiving long-term estrogen therapy at the time of percutaneous transluminal coronary angioplasty. The control group comprised 200 nonusers of estrogen who were computer matched to the estrogen group. The 7-year survival rate was significantly better in the estrogen group (93\% vs 75\%, $P=$ .001 ), and the cardiovascular event rate was significantly lower in the estrogen group. ${ }^{10}$ Also, Khan and associates ${ }^{11}$ studied 129 women who underwent stenting of a single coronary artery. Estrogen treatment significantly reduced the need for repeat-target lesion revascularization (14/49 HRT users vs 30/56 nonusers). Sullivan and coworkers ${ }^{12}$ studied 1098 postmenopausal women undergoing CABG. Although only $92(8.4 \%)$ women were receiving HRT at the time of CABG, they had a 5-year survival rate of $98.8 \%$ compared with $82.3 \%$ for non-HRT users and a 10-year survival rate of $81.4 \%$ versus $65.1 \%$, respectively. In a multivariate analysis of long-term survival after CABG, use of HRT remained a significant predictor of survival. More recently, Shackelford and colleagues ${ }^{13}$ retrospectively studied 734 consecutive postmenopausal women undergoing isolated CABG from 1992 to 1997, of whom 102 (13.9\%) received estrogen. Univariate analysis showed that the perioperative mortality was significantly lower in the women receiving HRT (2.7\% vs 7.4\%), but stepwise logistic regression failed to confirm the significance of HRT use. Our mortality data from a larger population are strikingly similar to these. In our data, however, female sex with HRT was a significant independent predictor of a lower in-hospital mortality after isolated CABG.

Our study has several limitations apart from those inherent in a retrospective single-institution analysis. HRT data were not routinely recorded before May 1996. Neither were specific doses recorded. Despite a large sample of 4259 patients, only $27.3 \%$ were women, and of these, only $22 \%$ were receiving HRT. These small numbers decreased the statistical power for detecting differences in patterns of outcome that might have provided clues to the mechanism of benefit by HRT. A further limitation common to observational studies such as this one is that the apparent benefit 
of HRT could be the result of selection bias not apparent from the characteristics we have recorded. Our group of women receiving HRT compared with the group not receiving HRT were 2.4 years younger, were more often of white ethnicity, had less diabetes, had less congestive heart failure, had fewer diseased vessels, and were more frequently given an ITA graft. Conversely, they were more often smokers, had more hypertension, and had fewer vessels bypassed. Even though multivariate analysis identified age, congestive heart failure, class IV angina, white race, and use of an ITA in addition to HRT as independent predictors of mortality versus survival, a selection bias could account for the apparent benefit of HRT. These limitations could be further resolved by a prospective multi-institutional study designed to acquire larger numbers of female patients with more balanced comorbidity and additional characteristics recorded. A possible reduction in the CABG mortality and better outcome after angioplasty warrants such an effort.

After CABG in patients aged 55 years or older, women receiving HRT had a significantly lower in-hospital mortality than did women not receiving HRT. In fact, mortality after CABG in female HRT recipients was similar to that of men. We postulate that one or more of the cardiovascular actions of estrogen might benefit the coronary response to endoluminal injury of CABG. Randomized prospective trials are required to address the broader issues of HRT and cardiovascular health.

\section{References}

1. O'Connor GT, Morton JR, Diehl MJ, et al. Differences between men and women in hospital mortality associated with coronary artery graft surgery. Circulation. 1993;88:2104-10.

2. Edwards FH, Carey JS, Grover FL, Bero JW, Hartz RS. Impact of gender on coronary bypass operative mortality. Ann Thorac Surg. 1998;66:125-31.

3. Aldea GS, Gaudiani JM, Shapira OM, et al. Effect of gender on postoperative outcomes and hospital stays after coronary artery bypass grafting. Ann Thorac Surg. 1999;67:1097-103.

4. Abramov D, Tamariz MG, Sever JY, et al. The influence of gender on the outcome of coronary artery bypass surgery. Ann Thorac Surg. 2000;70:800-6.

5. Mosca L, Collins P, Herrington DM, et al. Hormone replacement therapy and cardiovascular disease. A statement for healthcare professionals from the American Heart Association. Circulation. 2001; 104:499-503.

6. Manson JE, Martin KA. Postmenopausal hormone replacement therapy. $N$ Engl J Med. 2001;345:34-40

7. Writing Group for the Women's Health Initiative Investigators. Risks and benefits of estrogen plus progesterone in healthy postmenopausal women: principal results from the Women's Health Initiative. Randomized controlled trial. JAMA. 2002;288:321-33.

8. Mendelsohn ME, Karas RH. The protective effects of estrogen on the cardiovascular system. $N$ Engl J Med. 1999;340:1801-11.

9. Oparil S, Chen SJ, Chen YF, Durand JN, Allen L, Thompson JA. Estrogen attenuates the adventitial contribution to neointima formation in injured rat carotid arteries. Cardiovasc Res. 1999;44:608-14.

10. O'Keefe JH, Kim SC, Hall RR, Cochran VC, Lawhorn SL, McCallister BD. Estrogen replacement therapy after coronary angioplasty in women. J Am Coll Cardiol. 1997;29:1-5.
11. Khan MA, Liu MW, Singh D, et al. Long-term (three years) effect of estrogen therapy on major adverse cardiac events in postmenopausal women after intracoronary stenting. Am J Cardiol. 2000;86:330-3.

12. Sullivan JM, El-Zeky F, Vander Zwaag R, Ramanathan KB. Effect on survival of estrogen replacement therapy after coronary artery bypass grafting. Am J Cardiol. 1997;79:847-50.

13. Shackelford DP, Daniels S, Hoffman MK, Chitwood R. Estrogen therapy in women undergoing coronary artery bypass grafting. Effect on surgical complications. Obstet Gynecol. 2000;95:732-5.

14. Hulley S, Grady D, Bush T, Furberg C, Herrington D, Riggs B. Randomized trial of estrogen plus progestin for secondary prevention of coronary heart disease in postmenopausal women. Heart and Estrogen/progestin Replacement Study (HERS) Research Group. JAMA. 1998;280:605-13.

15. Herrington DM, Rebboussin DM, Broshihan B, et al. Effects of estrogen replacement on the progression of coronary-artery atherosclerosis. N Engl J Med. 2000;343:522-9.

16. Shlipak MG, Angeja BG, Go AS, et al. Hormone therapy and inhospital survival after myocardial infarction in postmenopausal women. Circulation. 2001;2300-4.

17. Brett KM, Makans JH. Use of postmenopausal hormone replacement. Am J Epidemiol. 1997; 145:56-45.

18. Hartz RS, Rao AV, Plomondon ME, Grover FL, Shroyer LW. Effects of race, with or without gender, on operative mortality after coronary artery bypass grafting: a study using the Society of Thoracic Surgeons National Database. Ann Thorac Surg. 2001;71:512-20.

19. Mendelsohn ME, Karas RH. The time has come to stop letting the HERS tale wag the dogma. Circulation. 2001;104:2256-9.

20. Stampfer MJ, Colditz GA, Willett WC, Manson JE, Rosner B, Speizer FE. Postmenopausal estrogen therapy and cardiovascular disease. Ten-year follow-up from the Nurses' Health Study. N Engl J Med. 1991;325:756-62.

21. Grodstein F, Stampfer MJ, Manson JE, Colditz GA, Willett WC, Rosner B. Postmenopausal estrogen and progestin use and the risk of cardiovascular disease. $N$ Engl J Med. 1996;335:453-61.

22. Writing Group for the PEPI Trial. Effects of estrogen or estrogen/ progestin regimens on heart disease risk factors in postmenopausal women. The Postmenopausal Estrogen/Progestin Interventions (PEPI) Trial. JAMA. 1995;273:199-208.

23. White CR, Shelton J, Chen SJ, et al. Estrogen restores endothelial cell function in an experimental model of vascular injury. Circulation. 1997; $96: 1624-30$.

24. Mori T, Durand J, Chen YF, Thompson JA, Bakir S, Oparil S. Effects of short-term estrogen treatment on the neointimal response to balloon injury of rat carotid artery. Am J Cardiol. 2000;85:1276-9.

25. Chen SJ, Li H, Durand J, Oparil S, Chen YF. Estrogen reduces myointimal proliferation after balloon injury of the rat carotid artery. Circulation. 1996;93:577-84.

26. Oparil S, Levine RL, Chen SJ, Durand J, Chen YF. Sexually dimorphic response of the balloon-injured rat carotid artery to hormone treatment. Circulation. 1997;95:1301-7.

27. Bakir S, Mori T, Durand J, Chen YF, Thompson JA, Oparil S. Estrogen-induced vasoprotection is estrogen-receptor dependent. Evidence from the balloon-injured rat carotid artery model. Circulation. 2000;101:2342-4.

28. Li G, Chen YF, Kelpke SS, Oparil S, Thompson JA. Estrogen attenuates integrin-B3-dependent adventitial fibroblast migration after inhibition of osteopontin production in vascular smooth muscle cells. Circulation. 2000;101:2949-55.

29. Shi Y, O'Brien JE Jr, Fard A, Mannion JD, Wang D, Zalewski A. Adventitial myofibroblasts contribute to neointimal formation in injured porcine coronary arteries. Circulation. 1996;94:1655-64.

30. Koh KK, Mincemoyer R, Bui MN, et al. Effects of hormone-replacement therapy on fibrinolysis in postmenopausal women. $N$ Engl J Med. 1997;336:683-90.

31. Squadrito F, Altavila D, Squadrito G, et al. $17 \beta$-oestradiol reduces cardiac leukocyte accumulation in myocardial ischaemia reperfusion injury in rat. Eur J Pharmacol. 1997;335:185-92.

32. McHugh NA, Merrill GF, Powell SR. Estrogen diminishes postischemic hydroxyl radical production. Am J Physiol. 1998;274(suppl): H1950-4. 